\title{
PREVALÊNCIA DE ANTICORPOS CONTRA LEPTOSPIRA SPP. EM BOVINOS, CANINOS, EQUINOS, OVINOS E SUÍNOS DO MUNICÍPIO DE JAGUAPITÃ, ESTADO DO PARANÁ, BRASIL
}

\author{
V.Y. Hashimoto, J.L. Garcia, K.A.H. Spohr, F.G. da Silva, L.A. Alves, J.C. de Freitas \\ Universidade Estadual de Londrina, Departamento de Medicina Veterinária Preventiva, Centro de Ciências \\ Agrárias, CP 6001, CEP 86051-990, Londrina, PR, Brasil. E-mail: hashimotovanessa@gmail.com
}

\section{RESUMO}

\begin{abstract}
O objetivo deste trabalho foi determinar a prevalência de anticorpos contra Leptospira spp. em bovinos, caninos, equinos, ovinos e suínos, oriundos de 40 propriedades localizadas na área rural do Município de Jaguapitã, Estado do Paraná. Foram colhidas amostras de sangue de 370 bovinos, 161 equinos, 70 ovinos, 230 suínos e 97 caninos. O número de animais testados em cada propriedade, assim como o número de propriedades, foi determinado utilizando-se o programa Epi-info versão 6. As amostras de soros obtidas foram submetidas à prova de soroaglutinação microscópica (SAM) com 22 sorovares de Leptospira spp. Das 40 propriedades rurais pesquisadas, 38 (95,00\%) tiveram pelo menos um animal sororeagente na SAM e dos 928 animais estudados, 316 (34,08\%) apresentaram títulos $\geq 100$. A prevalência observada na espécie bovina foi de $42,43 \%$, com $87,18 \%$ das propriedades apresentando pelo menos um animal sororeagente. As prevalências de animais e propriedades reagentes para as demais espécies foram, respectivamente, 48,44\% e 87,18\% para equinos; $38,57 \%$ e $100 \%$ para ovinos; $18,70 \%$ e $28,00 \%$ para suínos; $11,34 \%$ e $31,25 \%$ para cães. O sorovar mais provável encontrado em bovinos foi Hardjo, em equinos Castellonis e Sentot, em ovinos, suínos e cães Icterohaemorrhagiae. Os resultados obtidos neste trabalho demonstram que as cinco espécies animais estudadas na área rural do Município de Jaguapitã tiveram contato com vários sorovares de Leptospira spp. Além disso, os resultados sorológicos sugerem uma possível transmissão do micro-organismo entre espécies animais, provavelmente em decorrência da exposição às mesmas fontes de infecção entre os animais estudados.
\end{abstract}

PALAVRAS-CHAVE: Anticorpos, soroaglutinação microscópica, Leptospira spp.

\section{ABSTRACT}

PREVALENCE OF ANTIBODIES AGAINST LEPTOSPIRA SPP. IN CATTLE, DOGS, HORSES, SHEEP AND SWINE OF JAGUAPITÃ, STATE OF PARANÁ, BRAZIL. The objective of this work was to determine the prevalence of antibodies against Leptospira spp. in cattle, dogs, horses, sheep and swine from 40 properties located in the rural area of Jaguapitã, state of Paraná, Brazil. Blood samples were taken from 370 cattle, 97 dogs, 161 horses, 70 sheep and 230 swine. The number of animals tested on each property, as well as the number of properties was determined using the program Epi-info version 6. Samples of serum were submitted to microscopic agglutination test (MAT) with 22 Leptospira spp. serovars. From the 40 rural properties investigated, $38(95.00 \%)$ had at least one positive animal according to SAM, and from 928 studied animals, $316(34.08 \%)$ presented titers $\geq 100$. The prevalence observed in the bovine species was $42.43 \%$, with $87.18 \%$ of the properties presenting at least one positive animal. The prevalence of animals and properties reactive for the other species were, respectively: $48.44 \%$ and $87.18 \%$ for horses; $38.57 \%$ and $100 \%$ for sheep; $18.70 \%$ and $28.00 \%$ for swine; $11.34 \%$ and $31.25 \%$ for dogs. The most frequent serovar in bovines was Hardjo, in horses Castellonis and Sentot, in sheep, swine and dogs Icterohaemorrhagiae. The results obtained in this study demonstrated that the 5 studied animal species in the rural area of Jaguapitã had contact with several Leptospira spp. serovars. Moreover, serological results suggest a possible transmission of Leptospira spp. between animal species, probably because of exposure to the same sources of infection among the animals studied.

KEY WORDS: Antibodies, microscopic agglutination test, Leptospira spp. 
A leptospirose é uma zoonose de distribuição mundial, com maior ocorrência em países tropicais e subtropicais, onde elevadas temperaturas e altos índices pluviométricos favorecem à sobrevivência do micro-organismo (LEVETT, 2001).

Esta enfermidade é comum nos animais de companhia, produção e silvestres que podem albergar leptospiras nos rins e ao eliminá-las pela urina, por períodos variáveis, contaminam o meio ambiente e atuam como fonte de infecção para outros animais, inclusive ao homem (FAINE et al., 1999). Nos animais domésticos, a infecção por Leptospira spp. depende de fatores como espécies animais de contato, sorovares existentes na região, condições ambientais e climáticas, além do manejo e oportunidades de infecção direta ou indireta (ELLIS, 1984).

Os diversos sorovares de Leptospira spp. podem, teoricamente, infectar qualquer espécie animal, mas na prática existem sorovares endêmicos em uma determinada região ou país, adaptados aos hospedeiros naturais, favorecendo assim sua preservação no meio ambiente(ElLIS, 1984). No Brasilas relaçõesentresorovar de Leptospira spp. e os hospedeiros preferenciais variam segundo a região, no entanto, de uma forma geral, os registros predominantessão:IcterohaemorrhagiaeeCopenhageni em roedores sinantrópicos; Grippotyphosa em marsupiais; Hardjoe Wolffiem bovídeos;Pomonae Icterohaemorrhagiae em suídeos, Icterohaemorrhagiae em equídeos, ovinos e caprinos; Canicola, Icterohaemorrhagiae e Copenhageni em cães (VASCONCELLOS, 1997; FAVERO et al., 2001; FAVERO et al., 2002).

O objetivo deste trabalho foi determinar a prevalência de anticorpos contra Leptospira spp. em bovinos, caninos, equinos, ovinos e suínos, oriundos de 40 propriedades localizadas na área rural do Município de Jaguapitã, Estado do Paraná.

No período de julho/1997 a julho/1998, foram colhidas amostras de sangue de todos os animais existentes em 40 propriedades rurais, localizadas no Município de Jaguapitã, Estado do Paraná.

As propriedades foram sorteadas ao acaso de um total de 506 imóveis rurais de Jaguapitã (INSTITUTO Nacionalde Colonizaçãoe Reforma Agrária, 1995). O Município de Jaguapitã localiza-se ao norte doEstado do Paraná, sendo formado por 10.613 habitantes, com 3.142 localizados na zonarural(IBGE,1991). Apresenta uma altitude de $650 \mathrm{~m}$, latitude $23^{\circ}$ sul e longitude $51^{\circ} \mathrm{W}$-GR, um clima subtropical úmido mesotérmico, com média de temperatura acima de $22^{\circ} \mathrm{C}$ no verão e abaixo de $18^{\circ} \mathrm{C}$ no inverno, extensão territorial de 463.138 km², com uma economia voltada à produção agropecuária e com uma população animal estimada em 37.817 bovinos, 2.650 suínos, 280 ovinos e 290 equinos (Instituto Paranaense De Desenvolvimento ECONÔMICO E SOCIAL, 1991). O município foi escolhido para o estudo devido a sua localização estratégica na região norte do Paraná, bem como sua proximidade com a Universidade Estadual de Londrina, além de já ter sido alvo de estudos de outras zoonoses.

Fizeram parte do estudo 370 bovinose 161 equinos oriundos de 39 propriedades, 70 ovinos de 8 propriedades, 230 suínos de 25 propriedades e 97 caninos de 32 propriedades. Para o cálculo da amostragem consideraram-seos dados populacionais doIPARDES InSTITUTOPARANAENSE DE DESENVOLVIMENTOECONÔMICOE Social (1991), bem como uma prevalência da doença de 50\%, uma precisão de $5 \%$ eumnível de significância de 5\% utilizando-se o programa Epi-info versão 6.

A colheita de sangue foi efetuada por meio de punção venosa da jugular externa ou braquial. As amostras de sangue foram acondicionadas em tubos de ensaio estéreis, identificadas de acordo com a espécie animal e centrifugadas para obtenção do soro, sendo então aliquotado em eppendorf® e armazenado a $-20^{\circ} \mathrm{C}$ até o momento de sua utilização.

Para detectar anticorpos contra Leptospira spp., todos os soros foram submetidos à prova de soroaglutinação microscópica (SAM) com antígenos vivos (FAINE et al., 1999). Foram utilizados 22 sorovares de referência: Australis, Autumnalis, Bataviae, Bratislava, Butembo, Canicola, Castellonis, Copenhageni, Cynopteri, Fortbragg, Grippotyphosa, Hardjo, Hebdomadis, Icterohaemorrhagiae, Panama, Pomona, Pyrogenes, Sentot, Shermani, Tarassovi, Whitcombi e Wolffi. Os antígenos foram mantidos a $28^{\circ} \mathrm{C}$ por 5 a 10 dias em meio EMJH (Difco®-USA) modificado pela adição de soro de coelho. As amostras de soros que na SAM apresentaram pelo menos $50 \%$ das leptospiras aglutinadas na diluição 1:100 foram consideradas reagentes e então diluídas geometricamente na razão dois para determinação da diluição máxima positiva. A análise dos resultados considerou como mais provável o sorovar que apresentou o maior título. Os animais que apresentaram títulos mais elevados idênticos para dois ou mais sorovares foram excluídas desta análise e considerados reatores para a Leptospira spp. Uma propriedadefoiconsiderada positiva quando apresentou pelo menos um animal sororeagente (título $\geq 100$ ).

Das 40 propriedades rurais pesquisadas, 38 $(95,00 \%)$ tiveram pelo menos um animal sororeagente na SAM e dos 928 animais estudados, 316 (34,08\%) apresentaram títulos $\geq 100$. Os maiores títulos encontrados foram $6.400 \mathrm{em}$ bovinos, $800 \mathrm{em}$ equinos e suínos, 400 em caninos e 200 em ovinos.

A prevalência observada na espécie bovina foi de $42,43 \%$, com $87,18 \%$ das propriedades apresentando pelo menos um animal sororeagente. As prevalências de animais e propriedades reagentes para as demais espécies foram, respectivamente, $48,44 \%$ e $87,18 \%$ para equinos; $38,57 \%$ e $100 \%$ para ovinos; $18,70 \%$ e $28,00 \%$ para suínos; $11,34 \%$ e $31,25 \%$ para cães.

Os sorovares mais prováveis detectados em bovinos, caninos, equinos, ovinos e suínos estão demonstrados na Tabela 1. 
A detecção de $316(34,05 \%)$ animais reagentes na SAM em 38 (95,00\%) propriedades rurais estudadas de Jaguapitã indica a presença de Leptospira spp. em grande parte do território deste município. A análise dos sorovares mais prováveis realizado no presente estudo mostrou maior prevalência dos sorovares Hardjo para a espécie bovina, Castellonis e Sentot para a espécie equina e Icterohaemorrhagiae para as espécies ovina, suína e canina. O predomínio de bovinos sororeatores para o sorovar Hardjo detectado neste trabalho concorda com outros estudos realizados no Brasil (FAVERo et al., 2001). MOREIRA (1994) considerou o sorovar Hardjo o mais patogênico para os bovinos, os quais se comportaram como reservatórios para a manutenção da doença no rebanho. Levantamentos sorológicos realizados em diversas regiões do Brasil têm demonstrado a ocorrência de anticorpos antileptospiras contra os sorovares Castellonis em equinos (НАsнiмото et al., 2007). O sorovar Castellonis, que normalmente circula na população de bovinos (ElLIS et al., 1983), sugere a proximidade entre os equinos estudados $\mathrm{e}$ com possíveis criações bovinas presentes na região. Apesar do sorovar Sentot ter sido considerado como um dos mais frequentes na espécie equina, são poucas as informações epidemiológicas a respeito da ocorrência deste sorovar no país. Entretanto, HERRMANN et al. (2004) e FAccioli et al. (2007) encontraram uma maior frequência de anticorpos contra o sorovar Sentot em ovinos e cães dos estados do Rio Grande do Sul e São Paulo. No Brasil, diversos estudos têm demonstrado a presença do sorovar Icterohaemorrhagiae nos exames sorológicos realizados em várias espécies animais domésticas. FAVEro et al. (2002) encontraram uma maior frequência de anticorpos contra o sorovar Icterohaemorrhagiae em ovinos e suínos de vários estados do Brasil. MagalHães et al. (2006) também encontraram uma alta frequência de anticorpos contra o sorovar Icterohaemorrhagiae em cães do Estado de São Paulo. Os ratos, e em especial as ratazanas, são considerados os principais reservatórios deste sorovar (FAINE, 1982), o que sugere a participação destes animais como fonte de infecção comum nas três espécies animais estudadas.

Tabela 1 - Sorovares mais prováveis detectados na prova de soroaglutinação microscópica (SAM), realizada com 22 sorovares de Leptospira spp. em bovinos, caninos, equinos, ovinos e suínos do Município de Jaguapitã, Estado do Paraná, Brasil, no período de julho/1997 a julho/1998.

\begin{tabular}{|c|c|c|c|c|c|}
\hline Sorovares* & Bovinos & Caninos & Equinos & Ovinos & Suínos \\
\hline Australis & - & - & 1 & - & - \\
\hline Autumnalis & 1 & 1 & 2 & - & 5 \\
\hline Bataviae & - & - & - & - & 1 \\
\hline Bratislava & 3 & - & - & - & - \\
\hline Butembo & - & - & 1 & - & 1 \\
\hline Castellonis & - & - & 7 & 2 & 2 \\
\hline Canicola & - & - & - & - & - \\
\hline Copenhageni & - & - & 2 & - & - \\
\hline Cynopteri & - & - & - & - & - \\
\hline Fortbragg & - & - & 1 & 1 & 1 \\
\hline Grippotyphosa & 2 & 2 & 6 & - & 1 \\
\hline Hardjo & 68 & 1 & 6 & 1 & - \\
\hline Hebdomadis & - & 1 & - & - & 4 \\
\hline Icterohaemorrhagiae & - & 3 & 2 & 17 & 24 \\
\hline Panama & - & - & - & - & - \\
\hline Pomona & 4 & - & 4 & - & - \\
\hline Pyrogenes & - & - & 2 & 1 & - \\
\hline Sentot & - & 1 & 7 & - & - \\
\hline Shermani & 11 & - & - & - & - \\
\hline Tarassovi & 3 & - & 1 & - & - \\
\hline Whitcombi & - & - & - & - & - \\
\hline Wolffi & 5 & - & 1 & - & - \\
\hline Total & 97 & 9 & 43 & 22 & 39 \\
\hline
\end{tabular}

*Sorovares mais prováveis: nesta análise, reações em que houve empate (título mais alto idêntico para dois ou mais sorovares) foram desconsideradas. 
De acordo com Bolin (1996), os sorovares de Leptospira spp. presentes em um uma determinada região estão associados à presença de um ou mais hospedeiros de manutenção, que servem como reservatórios naturais da infecção. Os hospedeiros de manutenção são, frequentemente, espécies silvestres e, algumas vezes, animais domésticos e de produção. Ocontato com os hospedeiros de manutenção ou com áreas contaminadas com a urina destes pode causar a infecção por Leptospira spp. em outras espécies.

Os resultados obtidos neste trabalho demonstraram que as cinco espécies animais estudadas na área rural do Município de Jaguapitã tiveram contato com vários sorovares de Leptospira spp. Além disso, os resultados sorológicos sugerem uma possível transmissão do micro-organismo entre espécies animais, provavelmente em decorrência da exposição às mesmas fontes de infecção entre os animais estudados. Outros estudos neste município, que incluam o isolamento e a tipificação das leptospiras encontradas, poderiam ajudar a entender a epidemiologia desta doença nos animais estudados.

\section{REFERÊNCIAS}

BOLIN, C. A. Diagnosis of leptospirosis: a reemerging disease of companion animals. Seminars in VeterinaryMedicine and Surgery (Small Animal), v.11, n.3, p.166-171, 1996.

ELLIS, W.A.; O’BRIEN, J.J.; NEILL, S.D. Leptospiral infection in horses in Northern Irelands. Serological and microbiological findings. Equine Veterinary Journal, v.15, n.4, p.317-320, 1983.

ELLIS, W.A. Bovine leptospirosis in the tropics: prevalence, pathogenesis and control. Preventive Veterinary Medicine, v.2, p.411-421, 1984.

FACCIOLI, P.Y.; CAMOSI, L.G.; LANGONI, H.; MENOZZI, B.D.; DAHER, S.R. Fatores de risco para leptospirose canina em bairro carente, Jardim Santa Elisa, Botucatu, São Paulo, Brasil. Veterinária e Zootecnia, v.14, n.2, p.306-314, 2007.

FAINE, S. Guidelines for the control of leptospirosis. Geneva: World Health Organization, 1982. (WHO Offset publication, 67).

FAINE, S.; ADLER, B.; BOLIN, C.; PEROLAT, P. Leptospira and leptospirosis. 2.ed. Melbourne: MediSci., 1999. $272 \mathrm{p}$.

FAVERO, A.C.M.; PINHEIRO, S.R.; VASCONCELLOS, S.A.; MORAIS, Z.M.; FERREIRA, F.; FERREIRA NETO, J.S. Leptospirose bovina - Variantes sorológicas predominantes em colheitas efetuadas no período de 1984 a 1997 em rebanhos de 21 Estados brasileiros. Arquivos do Instituto Biológico, São Paulo, v. 68, n.2, p.29-35, 2001.

FAVERO, A.C.M.; PINHEIRO, S.R.; VASCONCELLOS, S.A.; MORAIS, Z.M.; FERREIRA, F.; FERREIRA NETO, J.S. Sorovares de leptospiras predominantes em exames sorológicos de bubalinos, ovinos, caprinos, eqüinos, suínos e cães de diversos Estados brasileiros. Ciência Rural, v. 32, n.4, p.613-619, 2002.

HASHIMOTO, V.Y.; GONÇALVES, D.D.; SILVA, F.G.; OLIVEIRA, R.C.; ALVES, L.A.; REICHMANN, P.; MULLER, E.E.; FREITAS, J.C. Occurrence of antibodies against Leptospira spp. in horses of the urban area of Londrina, Paraná, Brazil. Revista do Instituto de Medicina Tropical de São Paulo, v.49, n.5, p.327-330, 2007.

HERRMANN, G.P.; LAGE, A.P.; MOREIRA, E.C.; HADADD, J.P.A.; RESENDE, J.R.; RODRIGUES, R.O.; LEITE, R.C. Soroprevalência de aglutininas anti-Leptospira spp. em ovinos nas Mesorregiões Sudeste e Sudoeste do Estado Rio Grande do Sul, Brasil. Ciência Rural, v.34, n.2, p.443-448, 2004.

INSTITUTO NACIONAL DE COLONIZAÇÃO E REFORMA AGRÁRIA (Brasil). Relação de Certificados de Cadastro e Notificações de Imóveis Rurais Emitidos, 714151Jaguapitã, PR: INCRA, 1995.

INSTITUTO PARANAENSE DE DESENVOLVIMENTO ECONÔMICO E SOCIAL. Caderno de Estatísticas Municipal. Jaguapitã, PR: IPARDES, 1991.

LEVETT, P.N. Leptospirosis. Clinical Microbiology Reviews, v.14, n.2, p. 296-326, 2001.

MAGALHÃES, D.F.; SILVA, J.A.; MOREIRA, E.C.; WILKE, V.M.L.; HADDAD, J.P.A.; MENESES, J.N.C. Prevalência de aglutininas anti-Leptospira interrogans em cães de Belo Horizonte, Minas Gerais, 2001 a 2002. Arquivo Brasileiro de Medicina Veterinária e Zootecnia, v.58, p.167-174, 2006.

MOREIRA, E.C. Avaliação de métodos para erradicação de leptospiroses em bovinos leiteiros. 1994. 110f. Tese (Doutorado) - Escola de Veterinária, Universidade Federal de Minas Gerais, Belo Horizonte, 1994

VASCONCELLOS, S.A.; BARBARINI JÚNIOR, O.; UMEHARA, O.; MORAIS, Z.M.; CORTEZ, A.; PINHEIRO, S.R.; FERREIRA, F.; FÁVERO, A.C.M.; FERREIRA NETO, J. S. Leptospirose bovina. Níveis de ocorrência e sorotipos predominantes em rebanhos dos Estados de Minas Gerais, São Paulo, Rio de Janeiro, Paraná, Rio Grande do Sul e Mato Grosso do Sul. Arquivos do Instituto Biológico, São Paulo, v.64, n.2, p.7-15, 1997.

Recebido em 3/4/09

Aceito em 20/7/10 